Para el efecto, pues; de tener la acción y poderla invocar no hay diferencia entre la parte misma y los terceros.

El interés de distinguir entre la parte misma y los terceros no existe sino desde el punto de vista de la prueba o pruebas a que pueden acudir unos y otros. deración:

Esas diferencias pueden subordinarse a la siguiente consi-

a). Si el acto se celebró por escrito, la parte misma que lo celebró debe demostrar el acto oculto también por escrito o por otra prueba de igual categoria, como confesión del contratante, principio de prueba por escrito, etc.

b). Sus herederos en la misma hipótesis de que el acto ostensible se celebró por escrito, para ejercitar la acción de simulación en los mismos casos en que su causante la hubiere querido y podido ejercitar, es decir, la acción que heredaron de su causante, también están obligados a dar la prueba del acto oculto por escrito, o un principio de prueba por escrito, o la confesión de la otra parte, complementadas en este caso por todo medio probatorio. Pero si el acto ostensible que celebró su causante, aún por escrito, lo fue en fraude de los derechos de la herencia, entonces el heredero o herederos que ejercitan la acción de simulación vienen a ser, no ya los sucesores que continúan la persona jurídica del causante, sino terceros respecto de él, que defraudó su derecho herencial, en la misma forma que son terceros respecto del mismo acto los acreedores personales del contratante que aparentemente disminuye el patrimonio que le sirve a los acreedores de prenda. Entonces la prueba que los herederos defraudados pueden usar para demostrar la existencia del acto oculto, ya no se limita solamente a la contraprueba escrita, ni a la confesión del otro contratante, ni al principio de prueba por escrito complementada por otros medios probatorios; entonces pueden acudir también a la prueba indicial, a la de presunción, a la de testigos y en general a todos los medios probatorios". (Casación de 30 de septiembre de 1936- G. J. Nro. 1911).

Para que los acreedores puedan intentar la acción de simulación contra el acto cumplido por el deudor en fraude de sus derechos, es menester demostrar que el patrimonio de este se menoscabó o disminuyó en tal forma que no es suficiente ya para responder al pago de sus obligaciones y además, que el crédito es anterior al acto incriminado. Los acreedores posteriores al acto simulado carecen de la acción.

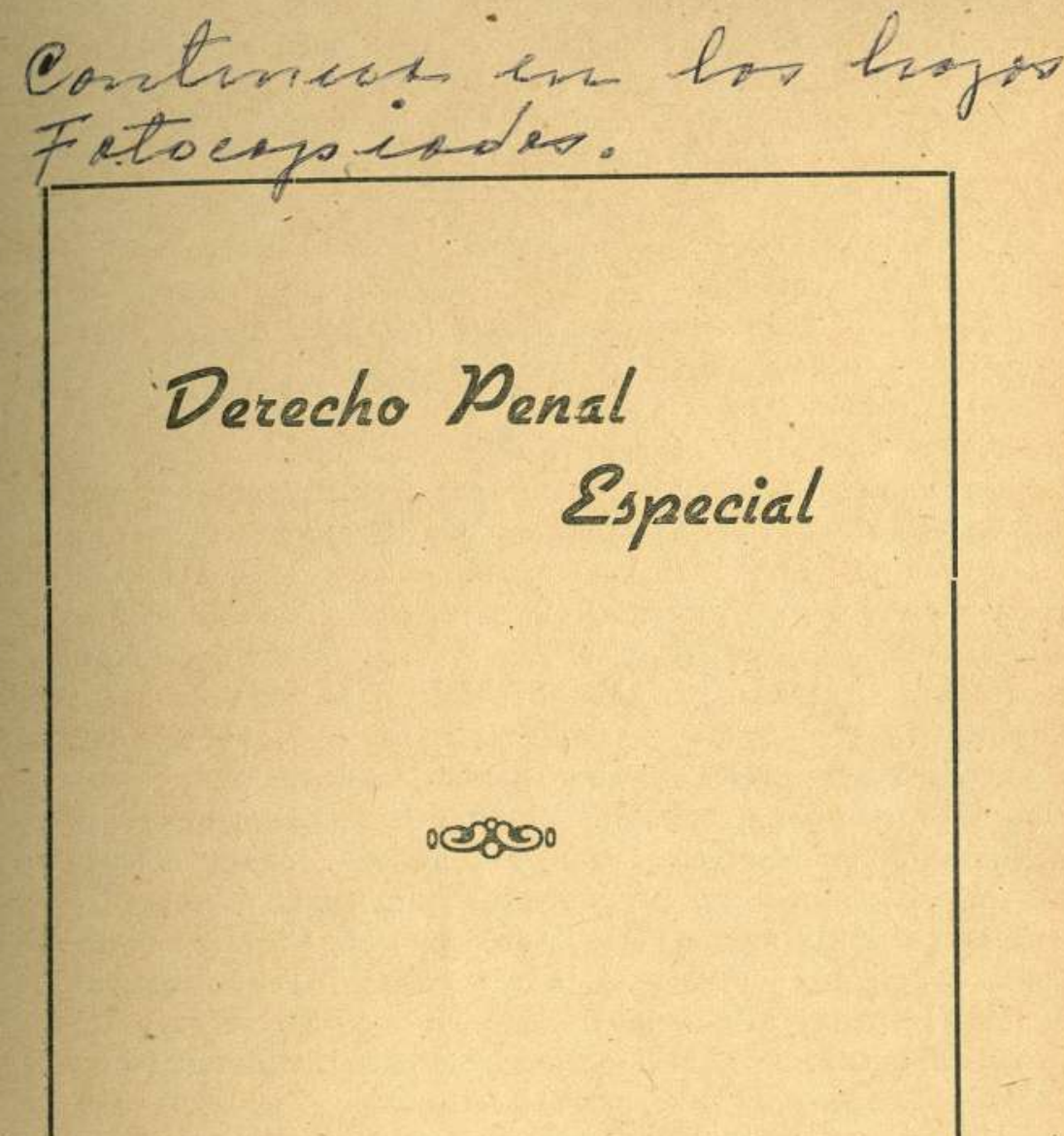

POR EL DR.

GUSTAVO RENDON G. 


\section{DELITOS CONTRA}

$\angle A$ ADMINISTRACION PUBLICA

Título III)

Este extenso Título de nuestro Código Penai se ocupa de los distintos hechos delictuosos considerados lesivos de la administración pública, entendida ésta no en el sentido completo de las múltiples actividades de orden oficial, sino en algunos de sus principales y ordinarios aspectos, como son los que se relacionan con los intereses del erario público, el decoro y rectitud de los funcionarios y la garantía, mediante una honesta gestión oficial, de muchos derechos de las personas. Es claro que otros Títulos de la Ley Penal se ocupan en particular de infracciones también lesivas de la misma administración, pero para reprimir especificamente hechos que por sus caracteristicas y modalidades, e inclusive por las condiciones del sujeto activo, exigen denominaciones más concretas. Tal ocurre, por ejemplo, con los delitos contra la administración de justicia.

En el orden del Título de que nos ocupamos los siguientes son los delitos a que se refiere: Peculado, Concusión, Cohecho, Negociaciones incompatibles con el ejercicio de funciones públicas, Prevaricato, Abuso de autoridad y otras infracciones, Ururpación de funciones públicas y Delitos contra los funcionarios públicos. Casi todos estos hechos exigen la calidad oficial del agente, el desempeño, así sea transitorio, de funciones públicas, pero algu- 
nos de ellos son susceptibles de cometerse por personas particulares.

\section{PECULADO}

En el lenguaje corriente, no en su verdadera significación jurídica, el peculado se entiende como un atentado de orden patrimonial en perjuicio del erario público cuando quien lo comete tiene a su cargo la administración de sus caudales. La denominación del hecho se deriva del término latino peculium, caudal. Frente a los - preceptos penales el peculado comprende no sólo la sustracción, distracción, alzamiento y otros hechos fraudulentos en perjuicio del Fisco, sino también la sola aplicación indebida de los caudales o efectos oficiales, de una parte, y de otra el delito puede integrarse cuando la acción recae sobre fondos no oficiales, si en su guarda, administración o depósito está comprometida la administración pública.

La anterior legislación "daba al peculado la denominación de delito contra la Hacienda Pública; otros Códigos le dan el nombre de malversación de caudales públicos, entendiendo por mal versar el hecho de invertir en forma indebida los caudales públicos (bienes en dinero o en especie que forman el patrimonio y la renta del Estado).

Examinaremos ahora, de acuerdo con la articulación del Código, las varias especies de peculado y las modalidades que el delito puede asumir.

\section{Aplicación oficial diferente}

"Artículo 150. El funcionario público que diere a los caudales o efectos que administra una aplicación oficial diferente de aquella a que están destinados, incurrirá en interdicción para ejercer empleo a cargo público, de uno a seis meses".

Si de ello resultare algún daño o perjuicio, se im pondrá además una multa de diez a quinientos pesos".

Esta forma de peculado entraña una malversación en cuanto se invierten por el funcionario administrador, ilicitamente, los caudales o efectos en usos distintos a los previamente fijados, aunque sea oficial la aplicación dada. Sus elementos constitutivos son:

a). Sujeto activo.-Unica y exclusivamente el funcionario público encargado de la administración de los caudales o efectos. publico encares oficiales aunque expresamente no lo diga la dispoque deben ser osta especie de peculado. Funcionarios sición, puede incuian ser sujetos activos de la infracción, como tamdistintos no podrian ser sujetos activos de participación o complicipoco los particulares, salvo los casos de participa en losticulos 19 , dad los que habrían de

20, 21 y 22 del C. P.

b). Objeto. - Materialmente el delito consiste en la aplicación oficial diferente de los caudales o efectos bajo la administración del funcionario responsable. tracción, aprovechamiento o uso indebido con fines personales, sino un abuso por parte del empleado, una burla a las leyes o disposiciones presuien atendidos por el Estado en forma ordenada y armónica.

Por caudales y efectos hay que entender todos los bienes propios a la Hacienda Pública, sean en dinero o en especie, documentos mercantiles, documentos de crédito emitidos por el Estado, muebles y enseres en general.

c). Dolo.-Aunque la infracción contemplada por el articulo 150 no exige el dolo que es propio a los hechos fraudulentos, no quiere ello decir que haya ausencia de intención criminal. La malversación de los caudales y efectos oficiales es siempre una actividad ilicita por contravenir disposiciones legales, a sabienda 3 de las cuales obra el agente para dar una aplicación distinta a dichos efectos o caudales. Cierto es que no hay el ánimo de un aprovechamiento personal por parte del agente y que inclusive puede obrar determinado por motivos de conveniencia pública, pero tales circunstancias no restan al hecho su intencionalidad.

Como el mal manejo de los fondos del erario en el caso que comentamos no afecta en sentido exacto el patrimonio oficia el Código es benévolo en la sanción, inclusive en el supuesto de ocasionar algún daño o perjuicio.

\section{Uso indebido}

"El uso indebido comprende en el delito de peculado las especies precisas de malversación fraudulenta o alzamiento de caudales, cuestión bien distinta de la contemplada en la anterior disposición. Para estructurar debidamente esta infracción y fijar con claridad sus modalidades conviene detenernos en el examen de sus elementos constitutivos. 
Sujeto activo.-Es también el funcionario público, pero tomado en un doble carácter: administrador y recaudador. Esta última actividad engloba funciones de manejo de caudales y percepción de ellos, como las que cumplen los tesoreros, administradores de rentas, etc. Hay, por lo tanto, una diferencia en las disposiciones que hablan del uso indebido y la que atrás dejamos comentada.

Objeto.-Cualquier uso indebido de los caudales o efectos por parte del empleado administrador o recaudador materializa la infraçción. Típicamente es un delito contra la propiedad en que el daño recae sobre intereses públicos, aunque también puede afectar el patrimonio particular.

El artículo 151 no dice que los caudales u otros objetos ha yan de ser oficiales porque parece haber sido criterio de la comisión redactora del Código asimilar a peculado ciertos hechos lesivos del patrimonio particular y susceptibles de cometer por al gunos funcionarios, por ejemplo, los jueces, caso de disponer de dineros confiados a su custodio o de otros bienes. No se ve muy claro que actuaciones de tal naturaleza puedan constituír peculado porque sus características más definidas son las de abuso de confianza.

En todo caso, el Código no se refiere a caudales públicos y las explicaciones que al respecto ofrecen las actas de la Comisión, en lo principal, son las siguientes:

_.....el doctor Cárdenas manifestó que no le parecía claro ni apropiado el término empleado por la anterior Comisión, es de cir, la expresión cosa pública; en su concepto sería mejor decir delitos contra la administración pública, que son las expresiones usadas por el Código italiano vigente. La expresión pública, en su opinión, es demasiado vaga y general, en esa forma puede comprender infracciones que no deben ser tratadas en esta parte del Código colombiano de delitos contra la Hacienda Pública, porque en esta forma se restringe demasiado el concepto de los delitos que tratan de estudiarse, pues quedarían muchos sin ser contemplados, como, por el ejemplo, el delito cometido por un juez que dispone del dinero correspondiente a un remate, delito que no puede decirse que sea contra la Hacienda Pública, porque esos dineros no corresponden al Fisco, y que tampoco puede encajarse con propiedad dentro del abuso de confianza porque se trata de un delito especial... ".........observa el doctor Escallón que eś necesario supri mir la palabra "públicos", para que al funcionario que haga uso indebido de caudales u otros objetos, que pueden ser de propiedad privada, se imponga la sanción correspondiente. De esta for ma se cobijará el caso contemplado por el doctor Cárdenas del Juez que dispone del dinero que esté bajo su cuidado como consecuencia de un remate

Dolo.-El uso indebido no es otra cosa que la apropiación, sustracción o uso fraudulento de los caudales u objetos con ánimo de aprovechamiento, bien sea para el agente o para un tercero. De ahí la diferencia con el peculado por simple cambio de destinación.

Disposiciones penales sobre peculado por uso indebido.

Tres artículos se ocupan de este delito aunque únicamente el primero comprende los elementos constitutivos de la infracción; los otros atienden a la regulación de la pena en consideración al hecho de producirse o nó el reintegro por el responsable.

"Artículo 151. El funcionario público que en cualquier forma haga uso indebido de los caudales $u$ otros objetos que por razón de sus funciones esté encargado de rê caudar o administrar, incurrirá en arresto de un mes a cuatro años y en interdicción de derechos y funciones públicas de un mes a dos años, siempre que tales sumas o efectos se reintegren antes de que se inicie la investigación criminal correspondiente.

Cabe observar respecto de la disposición transcrita que el reintegro (devolución total) juega preponderante papel en la medida de la responsabilidad, siempre y cuando se cumpla antes de dar principio a la acción penal contra el funcionario, lo que podría ocurrir, por ejemplo, al practicarse visita fiscal a la dependencia respectiva. Se nota el afán por parte de la ley de evitar en lo posible el daño efectivo a la administración all sancionar simplemente con arresto un delito de tanta entidad, pero bien puede justificarse porque evidentemente es un arrepentimiento eficaz en cuanto al daño del delito se refiere. Ya iniciada la investigación la situación es distinta, según disposiciones posteriores.

"Artículo 152. Si después de iniciada la investigación criminal $y$ antes de que se dicte la sentencia de primera instancia, o el veredicto del Jurado, si fuere el caso, 
reintegrare el responsable en todo o en parte lo sustraído o apropiado, o su valor, se impondrá la sanción de que trata el artículo siguiente, reducida hasta en la mitad, debiendo tenerse en cuenta, si hubiere lugar a ello, lo dispuesto en el artículo 60 ".

Lo que dispone el precedente artículo es una atenuación para el caso de operarse el reintegro en la oportunidad que es tablece. Permitiéndose la devolución parcial parece mal empleada la expresión "reintegrare", que supone volver en su total lo sustraído o apropiado.

La penalidad ordinaria del peculado es de uno a seis años de prisión, o presidio de cuatro a quince años, según la cuantía. Considerada esta tarifa de punición resulta inaplicable absolutamente el artículo 60 del C. P., porque no hay posibilidad de conversión de penas, ya que la prisión va de seis meses a ocho años $y$ el presidio de uno a veinticuatro años.

En cuanto a la oportunidad para el reintegro o devolución parcial de los valores o efectos, si se tiene en cuenta que el peculado compete juzgarlo a los Jueces Superiores, debe ser antes de proferirse el veredicto del Jurado, pues salvo casos excepcionales de fuero, el trámite es el indicado.

Cuando no hay reintegro o de haberlo no es en la oportunidad fijada por el artículo 152, el delito se sanciona en los términos de la siguiente disposición:

"Artículo 153. Si no se llevare a cabo el reintegro, se impondrá prisión de uno a seis años cuando el valor de lo sustraído o apropiado no pase de tres mil pesos, y presidio de cuatro a quince años cuando fuere mayor"

\section{Peculado culposo}

Por ser el empleado de manejo-administrador o recaudador-funcionario que debe llenar sus deberes oficiales no sólo con decoro y probidad sino con diligencia y prudencia, el Código eleva a la categoria de infracción penal la culpa cuando por causa de ella da lugar al extravío o pérdida de los caudales o efectos puestos bajo su custodia. Claro está que en este caso la pena no podria ser la correspondiente al peculado común, pero para seguridad de los interereses del fisco se impone al culpable la privación del empleo y la obligación de indemnizar pagando los caudales o e- fectos. Esto último no impide, naturalmente, que por las vías legales correspondientes, se exija del fiador el cumplimiento de sus obligaciones.

Instituciones de utilidad común

Las llamadas instituciones de utilidad común, que no son con propiedad dependencias o establecimientos oficiales tienen, no obstante, un régimen especial intervenido por el Estado, inclusive desde el punto de vista fiscal. De alli por qué haya asimilado el C. P. a peculado las defraudaciones que se puedan presentar en relación con ellas y ordenado aplicar las precedentes disposiciones, según el siguiente texto legal:

"Artículo 155. Las disposiciones de este capítulo se harán extensivas a los que por cualquier concepto se hallen encargados de fondos, rentas o efectos pertenecientes a un establecimiento de instrucción o de beneficencia".

Los fines y el alcance del artículo aparecen en las actas de la Comisión redactora del Código, particularmente en el concepto emitido por el Dr. Escallón, quien expresó: "Dice (el Dr. Escallón) para sustentar esta fórmula que estima oportuno equiparar los establecimientos de instrucción o beneficencia a las instituciones de carácter público, porque hay un interés especial en la protección de los deberes de las instituciones llamadas de utilidad común. Es preciso establecer una sanción especial y explicita tendiente a reprimir los abusos que se cometen con frecuencia por parte de los sindicos de comunidades y por distintas personas que invocando la caridad de los ciudadanos recolectan fondos que luégo no son destinados a la beneficencia. Hay también muchas sociedades que reciben subvenciones de las entidades públicas y luego por falta de control, le dan usos indébidos a tales subvenciones. Con el artículo propuesto se trata de establecer esa vigilancia por parte del estado para proteger de modo eficaz a las mismas instituciones para enterarse del fin que corren las subvenciones oficiales y las donaciones de los particulares. El que cometa un delito en el manejo de los dineros de esas instituciones se equiparará, para los fines alli previstos, a funcionarios públicos". 


\section{CONCUSION}

Este delito, conocido en otras legislaciones con el nombre de exacción legal y entre los romanos con el de crimen repentundarum, entraña la acción arbitraria de exigir contra derecho el funcionario público, en beneficio propio o de tercero, por excepción en beneficio de la administración, sumas o efectos representativos de utilidad pecuniaria. Es un delito contra la administración pública por la calidad del agente y porque precisamente obra en ejercicio de las atribuciones confiadas por la administración pública.

\section{Formas del delito}

Varias son las formas que esta infracción puede asumir pero en todas ellas son elementos comunes: condición de funcionario o empleado público del agente; abuso del cargo; interés patrimnnial; ilicitud del provecho, y dolo.

La primera forma de la concusión aparece en sus elementos concretos de la siguiente disposición:

"Artículo 156. El funcionario o empleado público o el encargado de un servicio público, que abusando de su cargo o de sus funciones, constriña o induzca a alguien a dar o prometer al mismo funcionario o a un tercero, dinero o cualquier otra utilidad, incurrirá en prisión de uno a seis años".

El delito, según los términos del artículo transcrito, es propio al funcionario o empleado público, lo mismo que a quien sin tener ese carácter está encargado de un servicio público, y para su integración deben llenarse estas condiciones:

a). Calidad oficial del agente;

b). Que la exacción se realice abusando el autor de su cargo o de sus funciones;

c). Que empleando los medios abusivos y en ejercicio de una función pública; el agente constriña - es decir coaccione o violente- o induzca a la víctima para que ésta dé o prometa, bien al concusionario o a un tercero, dinero $u$ otra utilidad patrimonialmente apreciable.

Parece ser que la infracción se perfeccionara con el sólo hecho de constreñir o inducir o, en otros términos, que no es indispensable que el ofendido pague o cumpla lo prometido.

El modus operandi del delito y la finalidad perseguida con él permiten observar que es fácil confundir la concusión con otros hechos ilícitos, principalmente el cohecho, la extorsión y el prevaricato. Pero en el fondo son infracciones bien diferentes. Así, mientras en la concusión el funcionario obra sobre el ofendido prevalido de su cargo para obligarlo a pagar o prometer, en el cohecho el particular no es conculcado sino que precisamente toma la iniciativa para corromper al funcionario y obtener de él una providencia o actuación. Sin duda hay casos difíciles de delimitar, pues, como comenta Carrara "no siempre el funcionario, y más bien muy rara vez, se vale de recursos tan torpes como el de exigir. Insinúa discreta e indirectamente, con actitudes, indicaciones, frases o palabras de valor entendido. Y es cla ro por demás que quien tal ve o escucha, entiende y se convence de que se defiende mejor la causa, buena o mala, ofreciendo dando, que exigiendo lisa y llanamente el cumplimiento del deber". Cómo resolver los casos dudosos? No podría en realidad darse un criterio preciso cuando el pago o la promesa están condicionados a una actuación determinada del funcionario. Quienes creen que debe estarse a los antecedentes del funcionario y resolver las dudas en su contra; otros opinan que debe entenderse el delito como cohecho, lo que compromente la responsabilidad del propio ofendido, cuando el acto del funcionario es injusto o contrario a la ley y favorable para aquél; por último, se defiende la tesis de la concusión si no hay prueba de la iniciativa del particular.

En nuestro concepto hay que plantear dos hipótesis: simple concusión existe cuando sin iniciativa del ofendido y sin finalidades proclives de su parte, entrega o promete lo que le es exigido por el funcionario arbitrariamente. En estos casos la igno rancia o el temor someten la voluntad de la victima; el delito adquiere complejidad cuando se exige remuneración, pago o promesa por parte del concusionario, para ejecutar las funciones del agente mal podría ser tildada la víctima de partícipe de un cohecho; pero si accede a entregar o prometer para un acto injusto o ilegal, la denominación adecuada del delito es cohecho y nó concusión.

Con el prevaricato no hay posibilidad de confusiones. El prevaricador obra movido única y exclusivamente por fuerzas sentimentales de que a infracciones, infracciones, como tampoco formular la tesis del concurso for- 
mal, dado que lo caracteristico de la concusión, aunque afecte el patrimonio del directamente ofendido, es el abuso de la función pública, es decir, obrar como empleado y dentro de las actividades oficiales correspondientes.

El dolo en el delito que sanciona el artículo 156 es bien característico: un ánimo de lucro, una intención fraudulenta, igual que en los delitos contra la propiedad. No admite responsabilidad culposa esta infracción, pues siempre se procede a sabiendas de que la actuación es arbitraria y abusiva y para un provecho personal del agente o de un tercero.

Un segundo caso de concusión lo trae la disposición que a continuación copiamos:

"Artículo 157. El funcionario o empleado público o el encargado de un servicio público, que abusando de su cargo o de sus funciones, y con el fin de obtener para sí o para otro un provecho ilícito, constriña o induzca a alguien a pagar impuesto o contribución, recargo, renta, rédito, salario o emolumento que legal mente no se deba, incurrirá en prisión de seis me. ses a cuatro años y en interdicción de derechos y funciones públicas por el mismo período.

Si empleare intimidación o invocare orden superior o mandamiento judicial, se aumentará la pena hasta en la mitad".

Concurren en este delito elementos que son comunes al de que trata el artículo 156, a saber: calidad del agente, abuso de funciones, ánimo particular de lucro (provecho ilícito) y acción delictiva (constreñir o inducir). La diferencia resulta del expediente fraudulento a que se recurre para consumar la infracción: mientras en el primer caso la exigencia de pago o de promesa no se disimula fingiendo el carácter oficial de lo reclamado, en el segundo la. exacción se produce atribuyendo causa, objeto y fines oficiales o públicos a las sumas que el particular se ve compelido a pagar. Se reviste, en consecuencia, de cierto legalismo la acción delictuosa del concusionario, al procurarse como impuesto o contribución, recargo, renta, rédito, etc., lo que en realidad es para provecho personal del agente o de un tercero.

El empleo de ciertos medios intimidativos, coercitivos o fraudulentos capaces de obrar con mayor eficacia sobre el ánimo de la víctima, es motivo para la calificación del delito en la for- ma señalada por el inciso segundo del artículo que comentamos.

Existe un caso de concusión en el que no obra el agente con un propósito personal o particular de lucro, lo que indica que puede obrar en beneficio de la misma administración o del servicio público a su cargo. La ausencia del dolo de lucro no quita al hecho sus condiciones delictuosas pero sí ofrece, naturalmente, menor gravedad. En los siguientes términos contempla el Código esta modalidad de la infracción:

"Artículo 158. Si al cometer el hecho de que trata el artículo anterior, no obrare el agente con el fin de obtener para sí o para otro un provecho ilícito, se le impondrá multa de ciento a mil pesos e interdicción de derechos y funciones públicas hasta por dos años".

Una última forma de concusión es la prevista en el artícu10 159. Desde cierto punto de vista el agente actúa en condiciones pasivas debido a que el dolo no es inicial sino ulterior. Comoven los casos de los artículos 156 y 157 el aprovechamiento es particular. La diferencia reside en que no hay una acción inicial ilícita; el agente se aprovecha del error ajeno para recibir o retener lo entregado por el ofendido. Dice asi la disposición pertinente:

"Artículo 159. El funcionario o empleado público o el encargado de un servicio público, que en el ejercicio de sus funciones, aprovechándose de un error ajeno reciba o retenga indebidamente para sí o para otro, dinero, efectos u obtenga alguna utilidad, incurrirá en prisión de seis meses a dos años y en multa de diez a mil pesos".

\section{COHECHO}

Hay desde el punto de vista de la administración pública y en particular respecto de la administración de justicia, en cuya probidad y celo confian los hombres de bien, dos delitos, imporcial ques por la gravedad que revisten, por el daño particular y sologran producen y por las formas más o menos inaparentes que logran alcanzar: son esos dos delitos el cohecho y el prevaricato, 
cuya integración jurídica difiere por la naturaleza del móvil que los inspira.

El cohecho es en sus delineamientos generales un acto de soborno o corrupción del funcionario para que obre en determina do sentido $u$ oportunidad, sin que sea preciso que su proceder sea contrario a la ley o a la justicia. Existe la infracción, sea le. gal o ilegal lo que pretenda obtenerse del funcionario, principalmente por el precio o la promesa que acepta para obrar. Claro está que si se cohecha para un acto irregular o contrario a los deberes oficiales el delito asume mayor gravedad.

Lo característico del cohecho es que el funcionario procede por precio o promesa remuneratoria provenientes del interesado en la actuación. Es el particular quien induce al funcionario a faltar a su deber estimulándole con la remuneración inmediata o futura, elemento éste que marca la diferencia principal con el delito de concusión. Sin embargo puede darse el delito de cohecho en que la iniciativa surja del propio funcionario, como ocurre en el caso previsto por el artículo 162, del cual hablaremos más adelante.

Como el cohecho requiere la acción inicial del particular, no sólo el funcionario es responsable del delito. También quien seduce o corrompe a éste, como es obvio.

Examinemos las distintas modalidades del delito, según las disposiciones del C. P., colombiano:

Cohecho para un acto legal y justo.

"Artículo 160. El funcionario o empleado público o la persona que transitoriamente desempeñe funciones públicas, que reciba indebidamente para sí o para un tercero dinero o dádivas, o acepte promesas remunerato rias, directas o indirectas, por acto que deba ejecutar en el desempeño de sus funciones, incurrirá in prisión de seis meses a cuatro años".

Son condiciones de la infracción:

a). Calidad oficial del agente, es decir que sea funciona rio o empleado público, lo que entraña servicio permanente, o persona transitoriamente investida de funciones públicas, como losi jurados, los árbitros, etc.

b). Aceptación indebida de dinero, dádivas, promesa de remuneración, directas o indirectas, todo lo cual entraña un pago irregular por actuaciones que no causan erogación, o que de causarla es por cantidad menor a la ofrecida y aceptada. Como lo expresa la disposición, no necesita ser directo el ofrecimiento; puede cumplirse por tercera persona y empleando recursos más o menos disimulados.

c). Acto legal y propio. En esta forma de cohecho no se seduce al funcionario para un acto arbitrario, injusto o ilícito, sino para obrar conforme a los deberes que le competen.

\section{Cohecho para un acto ilícito}

"Artículo 161. Si la admisión del dinero o de la dádiva, o la aceptación de las promesas, se verificare para omitir o retardar un acto propio del cargo o para ejecutar uno contrario a los deberes oficiales, la prisión será de uno a ocho años.

Si el responsable fuere un Juez o Magistrado del orden judicial o administrativo, la prisión será de dos a $\operatorname{diez}$ años".

Mientras en el caso primeramente examinado la corrupción se reduce al pago no debido de una actuación lícita y legal del funcionario, en este otro el delito reviste condiciones de mayor gravedad y circunstancias que lo hacen más lesivo de los in tereses de la administración, de las personas y de la moral.

Se cohecha, conforme al artículo 161 para fines abiertamente contrarios a la ley y a la justicia, como son: omitir un acto propio del cargo, que puede ser una verdadera acción-omisión; retardar su ejecución para que no produzca sus efectos en la oportunidad debida, o ejecutar uno contrario a sus deberes oficiales. Es evidente que al cohechar al funcionario para alguno de los fines expresados, el agente activo pretende obtener ventajas o beneficios con el consiguiente perjuicio para terceros o para la misma administración pública.

Si se atiende a las condiciones de gravedad que el delito reviste, a los perjuicios que de él pueden derivarse, al descrédito que causa a la administración pública y a la repugnancia que ofrece desde el punto de vista moral, cualquiera sea el funcionario que lo cometa, se explica suficientemente la alta penalidad establecida por la disposición, y la agravación consignada en el inciso segundo, cuando se trata de jueces o magistrados, lo mis- 
mo judiciales que administrativos, cuya imparcialidad y decoro son más imperativos.

Respecto a la agravación del delito en razón de la naturaleza del cargo es de observar que no es operante en el máximo (diez años de prisión) por cuanto el artículo 45 del Código sólo permite imponer ocho años de dicha pena, salvo que se entienda que hay lugar a la sustitución en los términos del artículo 60 ibidem.

\section{Cohecho por fraude}

"Articulo 162. El funcionario o empleado público, que al interve nir por razón de su cargo en la celebración de al gún contrato o licitación pública, en la liquidación de efectos o haberes públicos, o en el suministro de los mismos, se concertare con los interesados o especuladores para obtener determinado resultado, o usare de cualquier maniobra o artificio conducente a ese fin, incurrirá en prisión de uno a ocho años"

Contempla este artículo una forma de cohecho diferente de las anteriores y que en concreto se refiere a la participación fraudulenta del funcionario en operaciones que patrimonialmente interesan a las entidades públicas. Las dos primeras especies de la infracción abarcan toda clase de actos propios a los funcionarios públicos, cuando con relación a dichos actos el particular interesado ha obtenido lo pretendido mediante pago o promesa remuneratoria. En la última es simplementes una participación maliciosa y fraudulenta del empleado en operaciones en que debe oficialmente intervenir, bien sea por propia iniciativa o cohechado por un tercero.

El delito tiene estos elementos:

a).-Calidad oficial del agente;

b).-Que por razón de sus funciones oficiales intervenga en alguna de las operaciones a que se refiere la disposición, o sea: contratos, licitaciones públicas, liquidación de efectos o haberes públicos y suministro de los mismos.

c. - Concierto o acuerdo del agente con los interesados o especuladores, lo que puede resultar de la iniciativa de éstos seduciendo por precio o promesa de remuneración a aquél, o de la misma iniciativa del funcionario responsable, para conseguir un resultado determinado. No reclama la disposición que el resultado pretendido sea favorable a los interesados o que se produzca algún perjuicio. Tampoco exige pago o promesa al funcionario.

d. - En ausencia de concierto puede ser medio de comisión del delito el uso de maniobras o artificios para el fin pretendido, lo que entraña el fraude por parte del funcionario, y le da al delito aparentes condiciones de estafa.

\section{Responsabilidad del cohechador}

Artículo 164. El que diere u ofreciere dinero o dádivas a los funcionarios de que tratan los artículos anteriores, para los fines alli previstos, incurrirá en prisión de uno a cinco años.

Esta sanción se reducirá hasta en la mitad, si el dinero, dádiva $\mathbf{u}$ oferta no fueren aceptados"

En el delito de cohecho (lo propio ocurre en el falso testimonio) la responsabilidad no se radica en el sólo agente típico de la infracción, que para el caso requiere la calidad de funcionario público. El particular que obra como seductor o corruptor del funcionario para que proceda en determinada forma, estimulándolo con dinero u otras dádivas también comete cohecho, aunque es claro que su conducta es menos punible que la del cohechado.

La disposición sanciona dos casos distintos, ambos como delitos perfectos, no obstante que el segundo configura una especie de tentativa o un delito formal de propuesta para delinquir. que bien pudiera encajar en el artículo 211 del Código. El primer caso supone que el funcionario ha recibido o aceptado la remuneración y que por lo tanto son responsables del delito cohechado y cohechador; el segundo sólo produce la responsabilidad del particular.

\section{Cohecho aparente}

No otra denominación cabe dar al delito consagrado por el Código en la siguiente disposición:

"Artículo 165. Los funcionarios de que tratan los artículos ante. riores, que recibieren dinero o dádivas, ofrecidas en consideración a su cargo, por personas que tengan algún asunto pendiente en su respectivo Despacho, incurrirán en la interdicción de derechos y funciones públicas de uno a seis años". 
No se configura con sus propios y precisos elementos el delito de cohecho en el caso previsto por esta disposición por cuanto quien pudiera estar interesado en inclinar el ánimo del funcionario para determinada actuación no obra directa ni especificamente en tal sentido. Es más bien un proceder indirecto, hasta cierto punto equivoco, que si no compromente con poder coactivo eficaz la voluntad del funcionario, evidentemente le resta libertad para sus decisiones, máxime si legalmente han de ser contrarias al dador. Ello justifica la prohibición a los empleados públicos de recibir dinero o dádivas, cuando son ofrecidas en con sideración al cargo oficial y por personas que tienen asuntos pendientes en su respectivo Despacho. No importa que el funcionario conserve su integridad y que no obedezca en sus decisiones al interés o a la gratitud. Potencialmente hay una amenaza para la administración y de cierto el hecho entraña una corruptela inaceptable.

\section{NEGOCIACIONES INCOMPATIBLES CON EL EJERCICIO DE FUNCIONES PUBLICAS}

Una sola disposición contiene este capítulo para referirse a las infracciones en que no sólo los funcionarios o empleados públicos, sino las personas particulares cuando ejercen ciertas funciones confiadas por la autoridad, pueden incurrir, por resultar fraudulentas sus actuaciones e incompatibles con el cargo desempeñado.

En dos partes precisa descomponer la disposición para fijar su alcance: la primera se refiere a quienes propiamente desempeñan funciones públicas; la segunda a los particulares en ejercicio de algunos cargos en cuyo discernimiento o aceptación interviene la autoridad.

Predomina en estos hechos el concepto de la incompatibilidad para hacerlos dolosos, porque en verdad no exigen provecho ilicito o intención de causar perjuicio, aunque en cierta forma sean fraudulentos.

Establece la disposición:

"Artículo 167. E1 funcionario o empleado público o el que transitoriamente desempeñe funciones públicas, que directa $o$ indirectamente se interese en provecho pro- pio en cualquier clase de contrato u operación en que deba intervenir por razón de su cargo, incurrirá en interdicción perpetua de derechos y funciones públicas y en multa de ciento a tres mil pesos.

Esta disposición se aplicará a los peritos, árbitros o administradores particulares, respecto de los bienes o cosas en cuya tasación, partición o adjudicación intervengan o hubieren intervenido, y a los tutores, curadores o albaceas respecto de los pertenecientes a los respectivos pupilos o sucesiones".

Como expresamos antes, la primera parte de la disposición sanciona, por cuanto es ilicita, la conducta del funcionario que tocándole intervenir oficialmente en contratos $\mathrm{u}$ operaciones, en los que necesariamente hay intereses económicos, tanto de las entidades públicas como de los particulares, resuelve aprovecharse de su intervención en propio beneficio. La ley considera delictuoso este proceder aunque el provecho obtenido no sobrepase los limites correspondientes a la naturaleza de la operación, dado que el funcionario está legalmente obligado a no hacerse parte en tales gestiones. Es incompatible con su función.

Ya vimos que el empleo de medios fraudulentos, el concierto con los interesados en cuestiones de la misma indole da lugar al delito de cohecho, cuyos elementos examinamos al comentar el artículo 162.

El inciso segundo sanciona la conducta de otras personas, sin calidad de funcionarios o empleados públicos, que de manera directa y por razón de ciertos cargos intervienen en asuntos de indole patrimonial. En primer lugar, es incompatible con las funciones de perito, árbitro o administrador tomar interés personal en los bienes o cosas en cuya tasación, partición o adjudicación les compete intervenir; y en segundo, es incompatible con los cargos de tutor, curador o albacea una conducta semejante tratándose de los intereses patrimoniales representados o administrados.

Cuando a más del simple hecho que la disposición consagra y que reviste condiciones dolosas por causa de la incompatibilidad de funciones, peritos, árbitros, tutores, etc., proceden fraudulentamente con perjuicio de los intereses de otras personas, habría lugar a infracciones de otra indole, por ejemplo, delitos contra la propiedad. 


\section{PREVARICATO}

Al estudiar el delito de cohecho hacíamos notar que éste y el prevaricato son los hechos de mayor gravedad desde el punto de vista de la administración pública, como también los que potencialmente más amenazan precisos intereses y derechos de las personas en las actuaciones que corresponden a la administración de justicia.

En el concepto común se acepta que el prevaricato es delito propio a jueces y magistrados, pero en verdad no está circunscrito a esta clase de funcionarios, sino a todos aquellos que por la naturaleza de sus atribuciones tienen capacidad de actuar en la forma como lo previenen las disposiciones penales respectivas.

No es fácil dar una definición completa del prevaricato. En sentida general puede decirse que es toda actuación oficia violatoria de la ley e injusta en su convenido, cumplida a sabiendas, por simpatia o animadversión para los interesados.

Más fácil resulta entender su integración jurídica descomponiendo los elementos que la ley penal enuncia para las distintas formas del delito. Veamos la primera disposición.

"Artículo 168. El funcionario o empleado público o el que tran sitoriamente desempeñe funciones públicas, que a sabiendas dictare sentencia, resolución o dictamen contrarios a la ley, expresa o manifiestamente injustos, o rehusare, negare o retardare un acto propio de sus funciones, por simpatia hacia unos interesados o animadversión hacia otros, incurrirá en prisión de seis meses a cinco años.

Si se tratare de sentencia en juicio criminal, la pena será de dos a ocho años de presidio".

Obran como elementos del delito, según el texto transcrito, los siguientes:

a) Sujeto activo. Como es común a casi todos los delitos contra la administración pública, el agente típico del prevaricato es el funcionario o empleado público o el que transitoriamente desempeñe funciones públicas, porque es preciso tener capacidad para ejecutar el acto oficial que objetivamente constituye la infracción. Repetimos aquí que aunque de ordinario el prevaricato se presenta en actuaciones jurisdiccionales, como sentencias, autos y resoluciones en general, puede ocurrir en relación con actos de otra naturaleza, como dictámenes, veredictos, etc., (C. de P. P. Art. 529).

b). Elemento objetivo. Material u objetivamente el prevaricato se integra por dictar el funcionario un acto contrario a la ley, que puede ser, según los términos de la disposición, sentencia, resolución o dictamen, expresa o manifiestamente injusto; tencia, resolucion o dictardar un acto propio de sus funciones. o por rehusar, negar o retardar un acto propio de sus funciones.

En su estructuración puramente objetiva el delito no exige que el acto produzca o pueda producir perjuicios a terceros, ni que de manera inmediata quebrante un particular interés juri dico, distinto a los relacionados con la administracion pública.

Si se comparan las disposiciones formas de abuso de autorique se refieren al cohecho a identidad objetiva de tales infracciones, cuya tipificación depende esencialmente del dolo.

Desde el punto de vista que estamos examinando este delito conviene discriminar un poco la disposición atrás copiada: De una parte y refiriéndose el artículo a sentencia, resolución o dictamen, hace dos exigencias para configurar el delito, cuyo aldictamen, hace dos exigencias para configurar el delito, cuyo alex decir dictados contra disposiciones expas de la ley y por lo tanto con violación de preceptos positivos. Pero además y como principal condición del ilicito es necesario que ro además es decir, violatorios de los principios fundamentales del derecho, lesivos de las normas comunes de equidad. La combinación de estos dos requisitos es de notoria importancia porque de integrarse la infracción por el acto ser simplemente contrario a la ley se provocarian serios conflictos particularmente en relación con las normas de interpretación y aplicación de las leyes. Es, pues, necesario que el acto a más de ilegal sea injusto.

Cuando el prevaricato consiste en rehusar, negar o retardar un acto propio de sus funciones, forma ésta de actuación ilí cita que también puede ocurrir en el cohecho y en el abuso de autoridad, es claro que de manera implícita el hecho contiene la condición de ilegalidad de todo proceder oficial arbitrario. Para identificar como prevaricato una acción-omisión de las enunciadas hay que atender a la intención del agente, vale decir al mó vil, que el Código hace consistir en la simpatía del funcionario hacia unos interesados o animadversión hacia otros. Los motivo puramente afectivos (simpatía o desafecto) caracterizan el dolo 
del prevaricato, pero no sin razón se sostiene que tal dolo específico apenas se refiere a la segunda parte del inciso primero del artículo 168, puesto que en los casos de sentencia, resolución o dictamen es suficiente proceder a sabiendas. De este aspecto del problema nos ocuparemos a continuación.

c). Dolo. Hemos expresado repetidas veces que los delitos contra la administración pública, en particular los de concusión, cohecho, prevaricato y abuso de autoridad, ofrecen indentidad objetiva, lo que exige para una correcta tipificación el examen del elemento intencional o dolo. En el prevaricato, conceptuamos nosotros, el dolo lo integran, para los casos del artículo 168, el elemento a sabiendas y el móvil afectivo. Por el primero la actuación del funcionario es conscientemente ilegal e injusta; por el segundo, ella es determinada por simples motivos sentimentales, en los cuales encuentra el prevaricador intima satisfacción para su conducta.

Esta interpretación acerca del dolo en el prevaricato no es admitida en forma general. Por el contrario, muchos comentaristas y la misma jurisprudencia de la H. Corte Suprema de Justicia hacen la distinción que antes enunciamos: si se trata de sentencia, resolución o dictamen contrarios a la ley, expresa $\sigma$ manifiestamente injustos, el delito existe si el funcionario procedió a sabiendas; pero cuando rehusa, niega o retarda un acto propio de sus funciones entonces si se exige obrar por simpatía o desafecto. Ahora bien, aunque tal criterio pueda fundarse en la redacción y puntuación del artículo no lo compartimos porque necesariamente alguna motivación debe animar al prevaricador, lo mismo cuando dicta el fallo ilegal e injusto que cuando retarda, niega $\mathrm{u}$ omite, y es con base en esa motivación como se hace precisamente la identificación jurídica del hecho delictuoso.

Por ser de tanta importancia el problema del dolo en esta infracción transcribimos algunas doctrinas de la H. Corte Suprema de Justicia al respecto:

"Para reputar existente la enemistad o la animadversiónque es la expresión que trae el nuevo código penal al definir los elementos del prevaricato es menester que ocurran manifestaciones inequivocas de malquerencia y hostilidad del juez hacia la parte que se reputa injustamente perjudicada. El hecho al cual se atribuye la capacidad de engendrar enemistad no puede lógicamente invocarse como prueba de la misma.

"La animadversión del juez hacia una parte o la simpa- tia por la tampoco bastan. Es menester que aparezca que unotivo, o por ambos, se produjo el acto acusado de ilegal. De aquí que la Sala considere que lo fundamental para la ilegal. De án del dolo en la providencia manifiestamente ilegal e demostracion el elemento A SABIENDAS. Producida esta prueba, injusta efecto o desafecto cobra la eficacia probatoria que de ella se exige en conjunto, o sea la virtud de haber determinado al juez a violar la ley".

Obrar A SABIENDAS es, desde luego, saber de modo cierto lo que sc hace y el fin perseguido. Siguiendo los términos del art. 168 del C. P., es preciso que el juez obre a sabiendas, primero, de que su decisión es contraria a la ley y, segundo, de que con ella comete una injusticia flagrante. Y puesto que se trata de un hecho esencialmente doloso, el A SABIENDAS del prevaricato no es otra cosa que el elemento intencional por el doble aspecto de violar la ley y de faltar a la justicia. Pudiera decirse también que es la conciencia de la injusticia cometida en virtud de la violación deliberada de la ley"

"A juicio de la Sala, la prueba del elemento A SABIENDAS aque se refiere el art. 168 del C. P., se produce cuando el funcionario resuelve arbitrariamente, sin tomar para nada en cuenta la ley, o cuando la aplicación en sentido notoriamente contrario a lo que ella expresa, lesionan manifiestamente, sin razón ni justicia, los derechos de las personas o la seguridad social. Y habrá casos en que el ánimo y el móvil resulten probados al tiempo con documentos o por medio de manifestaciones verbales del propio sindicado".

"El obrar A SABIENDAS, lo mismo que el motivo determinante del -prevaricato, son factores internos cuya concurren cia no puede deducirse de simples conjeturas. Es menester que los hechos externos los revelen y que la prueba aducida al respecto sea completa. Sin ella el delito no podrá darse por existente y por tanto se careceria de base para abrir causa criminal contra el acusado".

\section{Calificación del delito}

El inciso segundo del artículo 168 señala una pena de presidio de dos a ocho años si el delito ocurre en relación con sentencia en juicio criminal. La ley atiende en este caso de agravación a la especial importancia que revisten los fallos de la justicia criminal, no sólo para la persona interesada en el proceso si- 


$$
-480-
$$

no para el ordenamiento social. Por ello es lo mismo que el failo ilegal o injusto sea favorable o desfavorable al acusado. En ambos casos el interés social resultaría afectado, y en el segundo, además, el interés particular.

Conviene hacer notar respecto del prevaricato y en particular a la forma calificada que comentamos, las siguientes cuestiones: a). El delito puede presentarse en la sentencia de primera instancia o en la de segunda e igualmente en la que se dictara en virtud de recurso extraordinario; b).El delito no se modifica por el hecho de ser revocada la sentencia ilegal e injusta, lo que quiere decir que alcanza su consumación aunque no produzca el daño pretendido c). Toda autoridad jurisdiccional competente para decidir en procesos penales cae bajo la sanción agravada del prevaricato caso de incurrir en el hecho que la disposición contempla. Una duda podria presentarse y es la relativa al juzgamiento de contravenciones, por cuanto no constituyen legalmente delitos ni dan lugar, en términos exactos, a juicio criminal. Somos del parecer que una decisión del funcionario competente en esta materia - contravenciones- no permitiría la aplicación del inciso segundo del artículo 168 ; d). Debe entenderse por sentencia, para los efectos de la calificación, no sólo la providencia con que se da término al juicio, agotados todos los trámites de la causa. sino toda decisión de fondo que ponga término al proceso penal, como la sentencia del artículo 153 del C. de P. P., o el sobreseimiento definitivo.

\section{Forma especial de prevaricato.}

Se incurre en prevaricato no sólo por una decisión contraria a la ley e injusta o por un acto arbitrario del funcionario, que son los hechos a que se contrae el artículo 168 , sino que e! delito puede presentarse por simples gestiones del funcionario indicativas de su interés por alguna o algunas de las personas que litigan ante él. Esta forma del delito la configura así el Código:

"Artículo 169. Los funcionarios de que trata el artículo anterior que, por iguales móviles y en perjuicio de terceros. asesoren o patrocinen a las personas que ante, ellos litiguen o gestionen, incurrirán en prisión de seis meses a tres años".

$$
-481-
$$

Son condiciones propias de este delito:

a) del artículo 168 ;

unos interesados o animadversión hacia otros:

Que los que litigan o c). Qu Despacho sean en perjuicio de terceros;

gestionan en su Despacho seansista en asesorar o patrocinar.

d). Que su ayuda consista en assosición lo formula, sólo

El prevaricato, tal como esta disposicion las personas en cuyo faentraña una situación de privilegio para las personas en cucilitánvor el funcionario resuelve asesorarlas on la actuación doles el éxito de sus pretensiones, orientandolas no favorecidas, en y colocando, por consiguiente, a las partes

condiciones de inferioridad. Para la integración del delito debe tenerse presente caso de juicio de terceros, elemento que es propio unicamente al casia habe de preesta disposicato. 